\title{
Timeline of Gas Production under Anaerobic Conditions
}

\section{Bernadette E Teleky* and Mugur C Bălan}

Department of Mechanical Engineering, Technical University of Cluj-Napoca, Romania

\begin{abstract}
For the study of biogas production by anaerobic digestion of lignocellulose substrate, it was designed an experiment in which the quantity of gas released by the anaerobic hydrogen producing bacteria was measured. The experiment aimed to highlight the differences occurred in the quantity and composition of the gas provided in 5 consecutive experiments conducted in similar conditions. The experimental data were processed and it was analysed the timeline evolution of the gas production rate of which kinetic was numerically modelled by several three-parameter logistic functions. Even being a preliminary study, it is innovative because it combines experiment with simulation and it proved two mathematical models, based on Gompertz and logistic functions. It was found that the anaerobic digestion process with hydrogen production has a sigmoid dependence on time.
\end{abstract}

Keywords: Anaerobic digestion; Gas production; Lignocellulose biomass; Numerical modelling; Logistic functions

\section{Introduction}

The anaerobic digestion of biomass can be considered one of the most promising technologies for renewable energy production. It can provide biogas with high energy potential and thus it represents a possible alternative to the conventional fuels like coal, wood, petroleum, natural gas and others.

Hydrogen production using agricultural residues and wastes [1] like cheese whey $[2,3]$, rice straw [4], wheat straw [5,6], manure [7], municipal waste [8], and food waste [9] has received special attention currently.

Biomass rich in lignocellulose, like energy crops, agricultural and forest management residues [10] and municipal wastes is a versatile renewable energy source [11]. It can replace fossil fuels in power and heat generation and natural gas in the production of chemicals. Additionally it can also serve as a gaseous fuel [12].

Biomass with high lignocellulose content, like wheat straw and other agricultural residues have a very compact crystalline structure, thus they are hardly degradable [13] and conversion to hydrogen through anaerobic fermentation is very hard [14]. Because wheat straw residues are widespread all over the world and it could be gained at low cost, its conversion to hydrogen is intensively studied $[1,10]$, and could be considered quite a good substrate for hydrogen production [15].

Straw is one of the major crop residues in Europe that could be used for the production of biogas [16]. Wheat straw generally consists of around (7.4-8.2)\% lignin, $46 \%$ cellulose, $33.7 \%$ hemicellulose, and forasmuch lignin physically shield the cellulose and hemicellulose parts and it can be hardly degraded microbiologically under anoxic conditions in engineered systems [17]. Because straw has a high carbon-nitrogen ratio $(\mathrm{C} / \mathrm{N})$ and low levels of trace elements it limits the activity and growth of microbes. In order to stimulate the anaerobic digestion, different pre-treatment methods can be used $[18,19]$.

Mathematical models can be used to explain effects of the various components and to perform different behavioural predictions [20]. Many studies use mathematical models to study the microorganism growth, cumulative hydrogen production [21]. Between the many kinetic models of the gas production, are well known Gompertz [22,23] or logistic $[20,24]$.
The aim of this study was to model, from quantitative point of view, the gas production through anaerobic fermentation of straw with hydrogen producing microorganisms. A series of five experiments was conducted and in each one the production of hydrogen was recorded. A series of alternative models for the timeline gas production were fitted and the best alternatives were selected.

\section{Material and Methods}

\section{Samples gathering}

Sediments samples, as source of digesting microorganisms, were taken from Lake Héviz (Hungary) at the temperature of $29^{\circ} \mathrm{C}$ and at the $\mathrm{pH}$ of (7.1-7.2) in April 18, 2011. In the sampling process were considered two different areas of the lake: one was located in a foreshore zone vegetated with plants from the Typhaceae family being labelled "Typha" and the other one was located in the middle of the lake being labelled "Sediment". The samples were preserved at $-20^{\circ} \mathrm{C}$ until the beginning of the experiments.

\section{Design of experiment}

Each experiment of anaerobic digestion with gas production was conducted with the same quantity of straw as substrate $(250 \mathrm{mg})$, the same quantity of culture media $(25 \mathrm{ml})$, and the same number of microorganisms $\left(10^{6}\right)$. The process of preparation for all the components introduced in the culture bottles is presented in Figure 1.

The straw substrate was prepared by chopping followed by sterilisation. The culture media was a DMSZ 640 modified and specially prepared with the composition indicated in Table 1.

The Cysteine is added as a source of sulphur and seeks to reduce the traces of oxygen. $\mathrm{NaOH}$ is added to adjust the $\mathrm{pH}$ to the value of 7.3. In order to remove the oxygen, this media was boiled in the microwave and

*Corresponding author: Bernadette E Teleky, Department of Mechanical Engineering, Technical University of Cluj-Napoca, Romania, Tel: 402-644-012-79; E-mail: tbernadette@mail.utcluj.ro

Received February 25, 2015; Accepted April 25, 2015; Published April 29, 2015

Citation: Teleky BE, Bălan MC (2015) A Timeline of Gas Production under Anaerobic Conditions. J Bioprocess Biotech 5: 222 doi:10.4172/2155-9821.1000222

Copyright: (c) 2015 Teleky BE, et al. This is an open-access article distributed under the terms of the Creative Commons Attribution License, which permits unrestricted use, distribution, and reproduction in any medium, provided the original author and source are credited. 


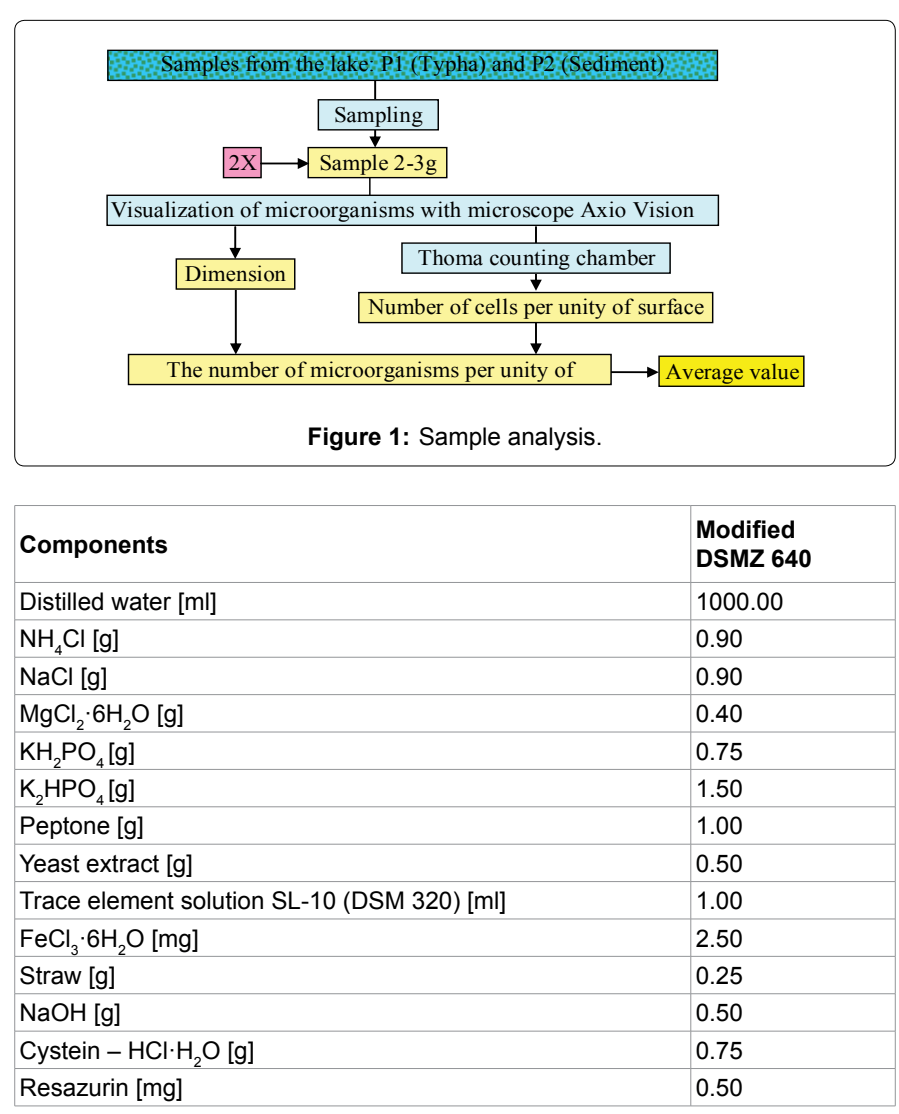

Table 1: Modified DSMZ 640 culture media.

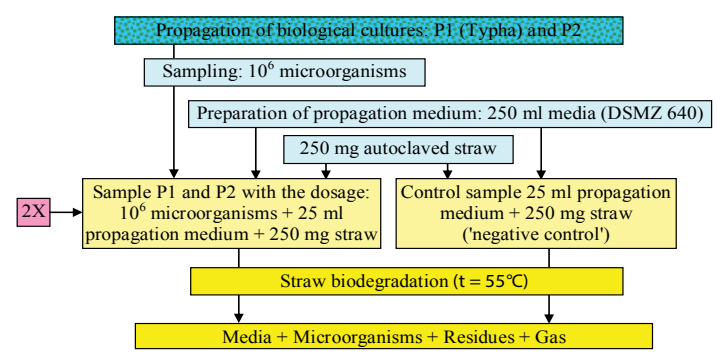

Figure 2: Propagation of the lignocellulose degrading bacteria.

\begin{tabular}{|c|c|c|c|c|c|c|}
\hline Model & Rational & Gompertz & Freundlich & Hill & Weibull & Logistic \\
\hline \multirow{2}{*}{ Eq. } & $a+b \cdot x$ & $e^{-e^{-}}$ & \multirow{2}{*}{$-a \cdot x^{b \cdot x^{-c}}$} & $a \cdot x^{d}$ & $1-e^{-(b \cdot(x-c))^{d}}$ & $a$ \\
\hline & $c+x$ & $a^{-1}$ & & $c^{d}+x^{d}$ & $a^{-1}$ & $1+e^{-b}$ \\
\hline
\end{tabular}

Table 2: Pre-selected alternatives for fit of the hydrogen production.

cooled down with nitrogen. In the anaerobic box it was measured and closed with butyl robber stopper and for sterilizing it was autoclaved for 30 minutes, at $121^{\circ} \mathrm{C}$ and at 2 bars.

The microorganisms were counted using an Axio Vision 4.8 microscope and a Thoma counting chamber. The preparation procedure was repeated two times for both Typha and Sediment.

Negative controls were made for control, to see that without the microorganisms from the Lake Hévíz, it produced negligible quantities of gas, and the cultures were not contaminated throughout the experiments.

The anaerobic digestion took place in each experiment, in the culture bottles at the temperature of $55^{\circ} \mathrm{C}$. Each experiment was continued until the exhausting of the substrate by the bacteria, revealed by the severe reduction of gas production. Each experiment was continued for (21-30) days. The components of gas production were hydrogen and $\mathrm{CO}_{2}$. Methane was not detected. Experiments succeeded each other following the scheme presented in Figure 2.

For this study were used the results obtained in 5 consecutive experiments.

\section{Data processing}

Some functions were considered to describe the time influence on the cumulative gas production throughout the experiments. Indirectly, the time is embedding the influence growing of microorganisms. The first two functions taken into account were Gompertz [25] and logistic [26].

Like in similar studies [27-29], a series of other possible alternatives of fit: Rational, Freundlich, Hill and Weibull were pre-selected for investigation from more than 100 available models, using FindGraph Software [30]. The pre-selected models, considered in the study, are presented in Table 2.

In all models, the variable $\mathrm{x}$ was assigned to the day of the observation in all the considered models and each model estimate the cumulative gas production, resulted from the experiments. The considered alternative models to fit were investigated to identify the adequate ones. The evaluation criterion for the evaluated models was the reliable confidences in their parameters. Into the analysis were considered independently 20 data sets, representing the data recorded for each of the 5 experiments, corresponding to the four bottles of culture: two bottles with Typha and to two bottles with Sediment. The expectance for correct modelling was that no more than $1 / 20=5 \%$ can have parameters with confidence not cancelling them.

\section{Results and Discussion}

\section{Gas production}

The results obtained from the 5 consecutive experiments are presented in Figure 3. The figured gas production is representing the normalized volume of gas, taking into account the temperature, the pressure and the volumes of gas, extracted at each measurement.

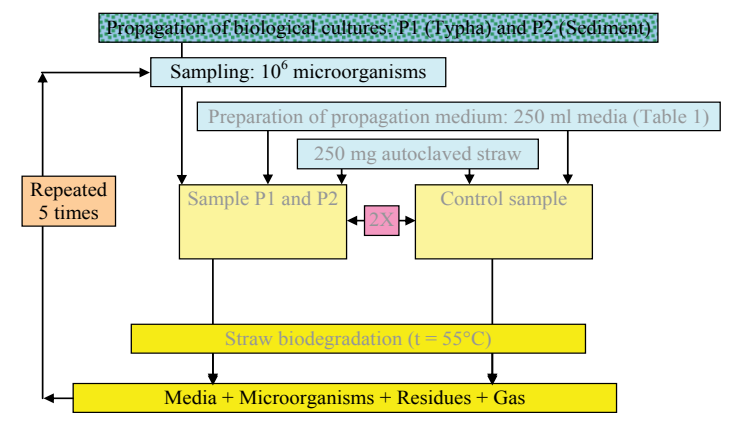

Figure 3: Experiment repetition. 
The highest gas production was observed for the cultures Typha "a" and Sediment "a", while the lowest gas production was observed for the culture Typha "b".

As it was expected, in the Negative controls culture bottles, no changes were observed during the entire period of all the experiments: the culture medium remained clear and the wheat straw substrate remained unmodified. The gas productions in the Negative controls culture bottles were insignificant, of $(0.1-0.2) \mathrm{ml}_{\mathrm{N}} / \mathrm{ml}$ until the day 10 of each experiment, when gas production completely stopped.

\section{Evaluation of models}

Four of the pre-selected models failed to correctly estimate the gas production. In Table 3 are presented failure fits for these alternatives. From all the evaluated models, only Gompertz and logistic, accomplished the selection criteria. For these models, the estimated of parameters, together with their relative confidence intervals are given in Table 4.

The presented results show that parameters of the model might change from one experiment to another. This inconsistency could be

\begin{tabular}{|l|l|l|l|l|}
\hline Model & Rational & Freundlich & Hill & Weibull \\
\hline Failure 1 & "Ta2" & "Ta2" & "Ta4" & "Ta2" \\
$\mathrm{a}=$ & $0.6 \pm 529 \%$ & $.1 \pm 122 \%$ & $3.5 \pm 296 \%$ & $1.1 \pm 7 \%$ \\
$\mathrm{~b}=$ & $1.8 \pm 33 \%$ & $1.2 \pm 96 \%$ & $61 \pm 617 \%$ & $.06 \pm 75 \%$ \\
$\mathrm{c}=$ & $17 \pm 86 \%$ & $0.15 \pm 103 \%$ & $0.8 \pm 75 \%$ & $-6 \pm 191 \%$ \\
$\mathrm{~d}=$ & & "Ta3" & "Tb3" & "Ta5" \\
\hline Failure 2 & "Ta3" & $0.1 \pm 135 \%$ & $1.3 \pm 117 \%$ & $1.3 \pm 2.5 \%$ \\
$\mathrm{a}=$ & $-.3 \pm 848 \%$ & $1.6 \pm 92 \%$ & $14 \pm 285 \%$ & $0.03 \pm 118 \%$ \\
$\mathrm{~b}=$ & $1.9 \pm 31 \%$ & $0.2 \pm 67 \%$ & $0.8 \pm 81 \%$ & $-23 \pm 170 \%$ \\
$\mathrm{c}=$ & $9.8 \pm 97 \%$ & $0.2 \pm 123 \%$ \\
$\mathrm{~d}=$ & & & $5 \pm 1 \%$ \\
\hline $\begin{array}{l}\text { Each of these models failed to accomplish selection criteria } \\
\text { (already 2/20 unreliable estimates of the parameters) }\end{array}$ \\
\hline
\end{tabular}

Table 3: Failure fits for some of the pre-selected alternatives. due to the slight differences in the quantity of substrate, in the quantity of culture media and/or in the number of microorganisms participating to the experiments. [31]:

Between the Gompertz and logistic functions are some differences

\section{- The Gompertz model is symmetric;}

- The logistic model is asymmetric.

Both models are used quite frequently in modelling of the experimental data as mentioned in [32-34]. When comparing the two models it should be taken into account that:

- The Gompertz model has a double exponential dependence, which is not the expected dependence for a kinetic of a chemical process.

- When the width of the confidence interval, given in Table 4, is averaged, one may find that the average of the relative width of the confidence intervals of the parameters for Gompertz model is $22.26 \%$ while for Logistic model is $20.27 \%$, providing a better estimation for the parameters of the digestion process.

Considering the logistic model more accurate than the Gompertz model, as follows are presented detailed results of the estimations with logistic model. Anyway further investigations, also with others models, can be performed, to search for even more accurate estimation models.

\section{The Logistic function model}

The total gas production during the experiments, estimated by the logistic model as function of time, is presented in Figure 4. The parameters of the Logistic function are those presented in Table 4.

For all the 5 experiments and for all cultures, the gas production was almost continuous in the first part and then stagnated in the last

\begin{tabular}{|c|c|c|c|c|c|c|}
\hline \multirow{2}{*}{\begin{tabular}{|l} 
Model \\
Eq.
\end{tabular}} & \multicolumn{3}{|l|}{ Gompertz } & \multicolumn{3}{|l|}{ Logistic } \\
\hline & \multicolumn{3}{|c|}{$a \cdot e^{-e^{-b \cdot(x-c)}}$} & \multicolumn{3}{|c|}{$a /\left(1+e^{-b \cdot(x-c)}\right)$} \\
\hline Estimates & a & $b$ & c & a & B & c \\
\hline Ta1 & $1.1 \pm 5.2 \%$ & $0.25 \pm 27 \%$ & $2.8 \pm 26 \%$ & $1.1 \pm 6.2 \%$ & $0.34 \pm 37 \%$ & $4.4 \pm 23 \%$ \\
\hline Ta2 & $1.1 \pm 7.2 \%$ & $0.16 \pm 24 \%$ & $5.2 \pm 17 \%$ & $1.1 \pm 5.4 \%$ & $0.24 \pm 21 \%$ & $7.4 \pm 12 \%$ \\
\hline Ta3 & $1.3 \pm 5.7 \%$ & $0.23 \pm 23 \%$ & $4.1 \pm 15 \%$ & $1.2 \pm 3.5 \%$ & $0.35 \pm 18 \%$ & $5.7 \pm 8.9 \%$ \\
\hline Ta4 & $1.2 \pm 28 \%$ & $0.14 \pm 66 \%$ & $5.5 \pm 51 \%$ & $1.1 \pm 25 \%$ & $0.20 \pm 62 \%$ & $8.0 \pm 47 \%$ \\
\hline Ta5 & $1.3 \pm 4.3 \%$ & $0.16 \pm 17 \%$ & $5.4 \pm 11 \%$ & $1.3 \pm 2.5 \%$ & $0.23 \pm 11 \%$ & $7.8 \pm 5.9 \%$ \\
\hline Tb1 & $1.2 \pm 3.7 \%$ & $0.33 \pm 23 \%$ & $2.6 \pm 20 \%$ & $1.2 \pm 4.9 \%$ & $0.46 \pm 34 \%$ & $3.8 \pm 20 \%$ \\
\hline Tb2 & $0.79 \pm 19 \%$ & $0.09 \pm 43 \%$ & $5.4 \pm 44 \%$ & $0.73 \pm 12 \%$ & $0.15 \pm 31 \%$ & $8.5 \pm 27 \%$ \\
\hline Tb3 & $0.78 \pm 9.6 \%$ & $0.18 \pm 34 \%$ & $3.7 \pm 26 \%$ & $0.75 \pm 5.6 \%$ & $0.27 \pm 24 \%$ & $5.7 \pm 15 \%$ \\
\hline Tb4 & $0.79 \pm 38 \%$ & $0.12 \pm 69 \%$ & $7.5 \pm 55 \%$ & $0.72 \pm 30 \%$ & $0.19 \pm 59 \%$ & $10 \pm 45 \%$ \\
\hline Tb5 & $0.64 \pm 3.6 \%$ & $0.26 \pm 24 \%$ & $3.3 \pm 20 \%$ & $0.63 \pm 3.6 \%$ & $0.35 \pm 27 \%$ & $4.9 \pm 14 \%$ \\
\hline Sa1 & $1.1 \pm 4.3 \%$ & $0.26 \pm 23 \%$ & $3.1 \pm 19 \%$ & $1.1 \pm 5.4 \%$ & $0.36 \pm 33 \%$ & $4.6 \pm 19 \%$ \\
\hline Sa2 & $1.2 \pm 5.3 \%$ & $0.29 \pm 33 \%$ & $2.3 \pm 34 \%$ & $1.2 \pm 5.6 \%$ & $0.4 \pm 6 \%$ & $3.7 \pm 26 \%$ \\
\hline Sa3 & $1.0 \pm 2.8 \%$ & $0.36 \pm 15 \%$ & $3.0 \pm 11 \%$ & $1.0 \pm 3.1 \%$ & $0.51 \pm 18 \%$ & $4.2 \pm 9.7 \%$ \\
\hline Sa4 & $0.88 \pm 13 \%$ & $0.29 \pm 61 \%$ & $5.7 \pm 23 \%$ & $0.83 \pm 11 \%$ & $0.62 \pm 79 \%$ & $6.6 \pm 19 \%$ \\
\hline Sa5 & $1.0 \pm 3.5 \%$ & $0.22 \pm 19 \%$ & $4.9 \pm 12 \%$ & $0.99 \pm 2 \%$ & $0.32 \pm 12 \%$ & $6.8 \pm 5.5 \%$ \\
\hline $\mathrm{Sb} 1$ & $1.1 \pm 5.5 \%$ & $0.3 \pm 32 \%$ & $2.7 \pm 28 \%$ & $1.1 \pm 6.4 \%$ & $0.41 \pm 43 \%$ & $4.1 \pm 25 \%$ \\
\hline Sb2 & $1.2 \pm 5.3 \%$ & $0.26 \pm 30 \%$ & $2.7 \pm 30 \%$ & $1.2 \pm 6 \%$ & $0.36 \pm 37 \%$ & $4.2 \pm 25 \%$ \\
\hline Sb3 & $1.2 \pm 4.2 \%$ & $0.35 \pm 24 \%$ & $2.6 \pm 19 \%$ & $1.2 \pm 5.4 \%$ & $0.48 \pm 33 \%$ & $3.8 \pm 19 \%$ \\
\hline $\mathrm{Sb} 4$ & $1.1 \pm 7.2 \%$ & $0.39 \pm 40 \%$ & $3.8 \pm 21 \%$ & $1.1 \pm 7.2 \%$ & $0.62 \pm 43 \%$ & $4.9 \pm 18 \%$ \\
\hline Sb5 & $1.2 \pm 3.2 \%$ & $0.35 \pm 26 \%$ & $2.7 \pm 22 \%$ & $1.2 \pm 3.6 \%$ & $0.47 \pm 32 \%$ & $3.8 \pm 18 \%$ \\
\hline
\end{tabular}

Table 4: Estimation of the parameters (a, b, c, d) along with their confidence. 


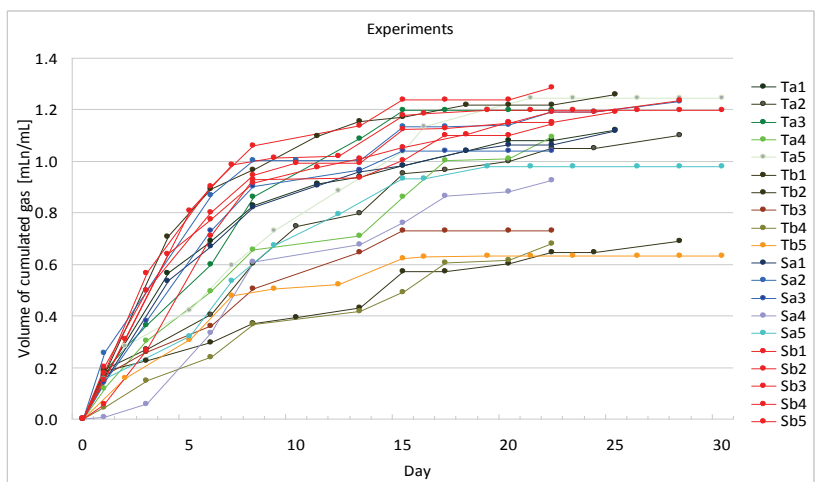

Figure 4: Volume of cumulated gas through the five repetitions of the experiment

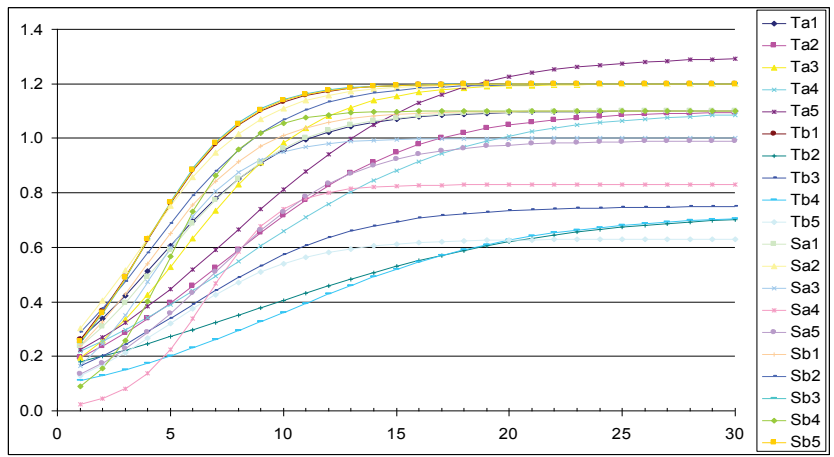

Figure 5: Digestion modelled by Logistic function as are estimated for the experiments.

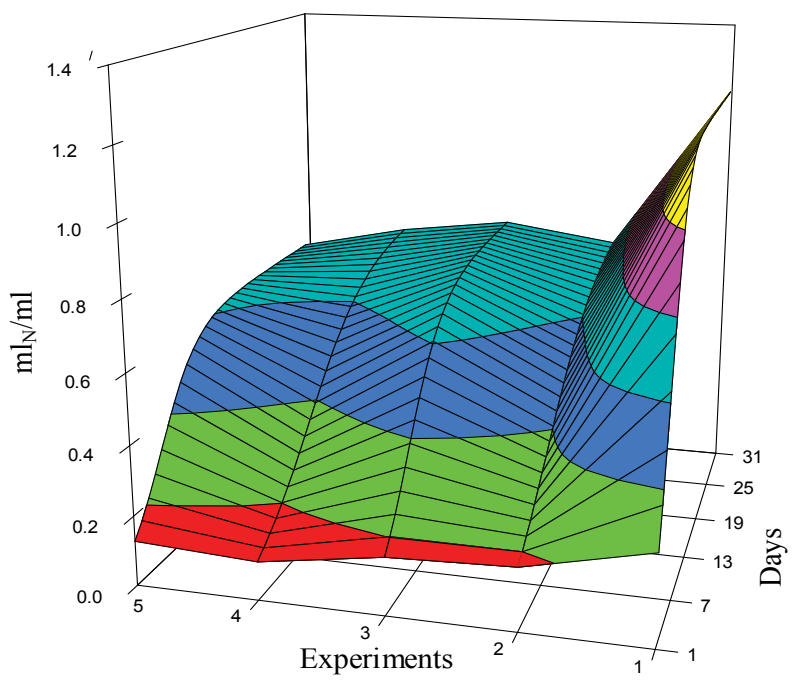

Figure 6: Digestion modelled for culture Typha B.

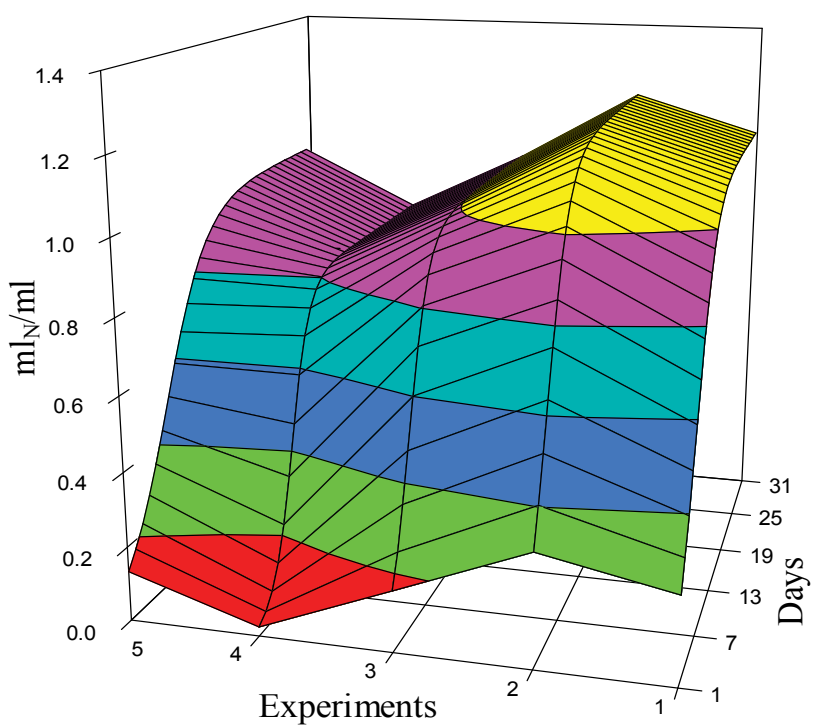

Figure 7: Digestion modelled for culture Sediment A.

period of experiments. This behaviour explain the sigmoid or "S" shape of the presented curves and simultaneous the sigmoid character of gas production dependence of time. Similar character of gas production in anaerobic digestion of biomass was reported in several references [3537].

As it can be observed, there are some significant differences between experiments:

- The shapes of the dependences may be related with the accessible surface of the straw to the microorganisms;

- The total quantity of the produced gas may be related with the total bioactive content of the straw.

The results of the modelling with the Logistic model are presented for each of the anaerobic digestion for each of the two types of cultures: Typha and Sediment and for each of the two culture bottles used in each experiment:

- The results for culture Typha "a” are presented in Figure 5;

- The results for culture Typha "b" are presented in Figure 6;

- The results for culture Sediment "a" are presented in Figure 7;

- The results for culture Sediment "b" are presented in Figure 8.

The synthetic analysis of the data presented in Figures $5-8$, is presented in Table 5 .

As it can be seen in the table, the culture "Typha a" had a gas production between $0.8-1.25 \mathrm{ml}_{\mathrm{N}} / \mathrm{ml}$, with the percentage of hydrogen in the produced gas was between $22.21 \%-34.06 \%$, leading to a hydrogen production of $0.18-0.43 \mathrm{ml}_{\mathrm{N}} / \mathrm{ml}$. The lowest gas production corresponded to the culture "Typha b" with $0.63-1.26 \mathrm{ml}_{\mathrm{N}} / \mathrm{ml}$, with the percentage of hydrogen in the produced gas was between $12.83 \%$ $22.91 \%$, leading to a hydrogen production of $0.08-0.29 \mathrm{ml}_{\mathrm{N}} / \mathrm{ml}$. The duration of the experiments was between 22-33 days for all cultures. The moment of stagnation was different and usually started at days 13 , 15 , or 18 . 


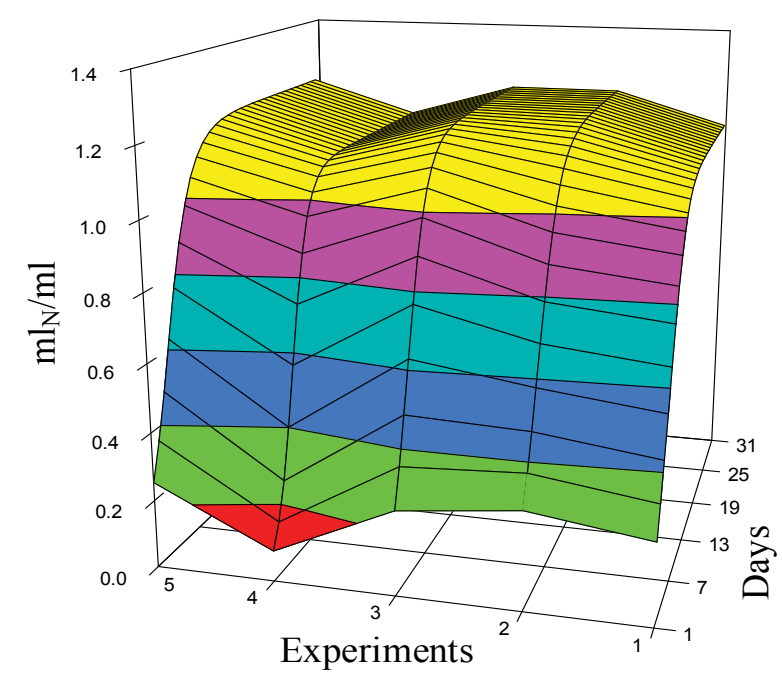

Figure 8: Digestion model for culture Sediment B.

It can be observed that hydrogen production obtained from the experiments and from correlated modelling, are in good agreement with similar values reported in the literature [38-40], but are under the values reported by $[15,41-43]$.

\section{Conclusion}

The study presents both experimental and modelling results concerning the gas production during the anaerobic digestion of biomass with high content of lignocellulose.

The analysis of the gas production revealed the sigmoid character of the gas production dependence of time in the anaerobic digestion of biomass. It was highlighted that this character is typical for this process, as it was previously reported in literature.

It were evaluated several models for the timeline of gas production and for all the considered models was analysed the expectance for correct modelling.

Two of the 6 models considered in the study passed the selection criterion and were considered correct. The two models are Gompertz and logistic. The study could not obtain clear evidence on about which model is the best one to be used for these estimates, and requires further investigation, but it could be stated that Logistic model is more accurate than Gompertz model.

The Logistic model was used to provide detailed information and characteristics of the gas production in anaerobic digestion of biomass. It was provided synthetic information about the following: duration of experiments, total gas production, moment of stagnation and hydrogen production.

The study proved that anaerobic digestion of biomass with lignocellulose presents high potential for hydrogen production to be used in energy applications.

\section{Acknowledgements}

This study is supported by the Sectoral Operational Programme for Human Resources Development POSDRU/159/1.5/S/137516 financed from the European Social Fund and by the Romanian Government. The

\begin{tabular}{|c|c|c|c|c|c|}
\hline Experiment & $\begin{array}{l}\text { Total gas } \\
\text { production } \\
\left.\text { [ml }_{\mathrm{N}} / \mathrm{ml}\right]\end{array}$ & $\begin{array}{l}\text { Duration of } \\
\text { experiment } \\
\text { [days] }\end{array}$ & $\begin{array}{l}\text { Moment of } \\
\text { stagnation } \\
\text { [day] }\end{array}$ & $\begin{array}{l}\text { Percentage of } \\
\text { hydrogen } \\
\text { production } \\
\text { [\%] }\end{array}$ & $\begin{array}{l}\text { Hydrogen } \\
\text { production } \\
{\left[\mathrm{ml}_{\mathrm{N}} / \mathrm{ml}\right]}\end{array}$ \\
\hline Typha 'a" & $0.80-1.25$ & $22-33$ & $15-33$ & $22.21-34.06$ & $0.18-0.43$ \\
\hline Typha "b" & $0.63-1.26$ & $22-33$ & $13-33$ & $12.83-22.91$ & $0.08-0.29$ \\
\hline $\begin{array}{l}\text { Sediment } \\
\text { "a" }\end{array}$ & $0.70-1.23$ & $22-33$ & $15-33$ & $24.31-28.67$ & $0.17-0.35$ \\
\hline $\begin{array}{l}\text { Sediment } \\
\text { "b" }\end{array}$ & $0.53-1.28$ & $22-33$ & $18-33$ & $2.11-25.65$ & $0.01-0.33$ \\
\hline
\end{tabular}

sTable 5: Main characteristics of the gas production in the experiments.

experimental part was supported by German Federal Environmental Foundation and Helmholtz Centre for Environmental Research - UFZ Leipzig, Germany.

\section{References}

1. Guo XM, Trably E, Latrille E, Carrère H, Steyer JP (2010) Hydrogen production from agricultural waste by dark fermentation: A review. Int J Hydrogen Energy 10: 10660-10673.

2. Frascari D, Cappelletti M, Mendes Jde S, Alberini A, Scimonelli F, et al (2013) A kinetic study of biohydrogen production from glucose, molasses and cheese whey by suspended and attached cells of Thermotoga neapolitana. Bioresour Technol 147: 553-561.

3. Kargi F, Eren NS, Ozmihci S (2012) Bio-hydrogen production from cheese whey powder (CWP) solution: Comparison of thermophilic and mesophilic dark fermentations. Int J Hydrogen Energy 37: 8338-8342.

4. Gu Y, Chen X, Liu Z, Zhou X, Zhang Y (2014) Effect of inoculum sources on the anaerobic digestion of rice straw. Bioresour Technol 158: 149-155.

5. Motte JC, Escudiè R, Beaufils N, Steyer JP, Bernet N, et al. (2013) Morphological structures of wheat straw strongly impacts its anaerobic digestion. Industrial Crops and Products 52: 695-701.

6. Nkemka VN, Murto M (2013) Biogas production from wheat straw in batch and UASB reactors: the roles of pretreatment and seaweed hydrolysate as a co-substrate. Bioresour Technol 128: 164-172.

7. Wang KS, Chen JH, Huang YH, Huang SL (2012) Integrated Taguchi method and response surface methodology to confirm hydrogen production by anaerobic fermentation of cow manure. Int J Hydrogen Energy 38: 45-53.

8. De Gioannis G, Muntoni A, Polettini A, Pomi R (2013) A review of dark fermentative hydrogen production from biodegradable municipal waste fractions. Waste Manag 33: 1345-1361.

9. Kobayashi T, Xu KQ, Li YY, Inamori Y (2012) Effect of sludge recirculation on characteristics of hydrogen production in a two-stage hydrogen-methane fermentation process treating food wastes. Int J Hydrogen Energy 37: 56025611.

10. Kaparaju P, Serrano M, Angelidaki I (2009) Effect of reactor configuration on biogas production from wheat straw hydrolysate. Bioresour Technol 100 6317-6323.

11. Sims REH (2004) Bioenergy options for a cleaner environment: in developed and developing countries. Elsevier, pp. 198.

12. Mosier N, Wyman C, Dale B, Elander R, Lee YY, et al. (2005) Features of promising technologies for pretreatment of lignocellulosic biomass. Bioresour Technol 96: 673-686.

13. Fan YT, Zhang YH, Zhang SF, Hou HW, Ren BZ (2006) Efficient conversion of wheat straw wastes into biohydrogen gas by cow dung compost. Bioresour Technol 97: 500-505.

14. Cao GL, Guo WQ, Wang AJ, Zhao L, Xu CJ, et al. (2012) Enhanced cellulosic hydrogen production from lime-treated cornstalk wastes using thermophilic anaerobic microflora. Int J Hydrogen Energy 37: 13161-13166.

15. Nasirian N, Almassi M, Minaei S, Widmann R (2011) Development of a method for biohydrogen production from wheat straw by dark fermentation. Int J Hydrogen Energy 36: 411-420. 
16. Kim SM, Dale BE (2003) Global potential bioethanol production from wasted crops and crop residues. Biomass and Bioenergy 26: 361- 375 .

17. Monlau F, BarakatA, Trably E, Dumas C, Steyer JP, et al. (2011) Lignocellulosic materials into biohydrogen and biomethane: impact of structural features and pre-treatment. Crit Rev Environ Sci Technol 43: 260-322.

18. Hendriks AT, Zeeman G (2009) Pretreatments to enhance the digestibility of lignocellulosic biomass. Bioresour Technol 100: 10-18.

19. Taherzadeh MJ, Karimi K (2008) Pretreatment of lignocellulosic wastes to improve ethanol and biogas production: a review. Int J Mol Sci 9: 1621-1651.

20. Wang J, Wan W (2008) Effect on temperature on fermentative hydrogen production by mixed cultures. Int J Hydrogen Energy 33: 5392-5397.

21. Argun H, Kargi F, Kapdan IK, Oztekin R (2008) Batch dark fermentation of powdered what starch to hydrogen gas: Effects of the initial substrate and biomass concentrations. Int J Hydrogen Energy 33: 6109-6115.

22. Kirkwood TB (2015) Deciphering death: a commentary on Gompertz (1825) 'On the nature of the function expressive of the law of human mortality, and on a new mode of determining the value of life contingencies'. Philos Trans R Soc Lond B Biol Sci 370 .

23. Sagnak R, Kargi F, Kapdan IK (2011) Bio-hydrogen production from acid hydrolyzed waste ground wheat by dark fermentation. Int J Hydrogen Energy 36: 12803-12809.

24. Ghatak MD, Mahanta P (2014) Comparison of kinetic models for biogas production rate from saw dust. IJRET 3: 248-254.

25. Waliszewski P, Konarski J (2005) A mystery of the Gompertz Function. In: Losa, GA, Merlini D, Nonnenmacher TF, Weibel ER (eds.) Fractals in Biology and Medicine. Birkhäuser, Switzerland, pp. 277-286.

26. Vieira S, Hoffmann R (1977) Comparison of the logistic and the Gompertz growth functions considering additive and multiplicative error terms. Appl Statist 26: 143-148

27. Boni MR, Sbaffoni S, Tuccinardi L, Viotti P (2013) Development and calibration of a model for biohydrogen production from organic waste. Waste Manag 33: 1128-1135.

28. Chen WH, Chen SY, Khanal SK, Sung S (2006) Kinetic study of biological hydrogen production by anaerobic fermentation. Int $\mathrm{J}$ Hydrogen Energy 31 2170-2178.

29. Mu Y, Yu HQ, Wang G (2007) A kinetic approach to anaerobic hydrogenproducing process. Water Res 41: 1152-1160.
30. http://www.uniphiz.com/

31. Nguimkeu P (2014) A simple selection test between the Gompertz and Logistic growth models. Technological Forecasting and Social Change 88 98-105.

32. Trappey CV, Wu HY (2008) An evaluation of the time-varying extended logistic, simple logistic, and Gompertz models for forecasting short product lifecycles. Advanced Engineering Informatics 22: 421- 430.

33. Chowdhury BR, Chakraborty R, Chaudhuri UR (2007) Validity of modified Gompertz and Logistic models in predicting cell growth of Pediococcus acidilactici $\mathrm{H}$ during the production of bacteriocin pediocin $\mathrm{AcH}$. J Food Eng 80: 1171-1176.

34. Wilson DL (1994) The analysis of survival (mortality) data: fitting Gompertz, Weibull, and logistic functions. Mech Ageing Dev 74: 15-33.

35. Bah H, Zhang W, Wu S, Qi D, Kizito S, et al. (2014) Evaluation of batch anaerobic co-digestion of palm pressed fiber and cattle manure under mesophilic conditions. Waste Manag 34:1984-1991.

36. Krishania M, Vijay VK, Chandra R (2013) Methane fermentation and kinetics of wheat straw pretreated substrates co-digested with cattle manure in batch assay. Energy 57: 359-367.

37. Xu F, Wang ZW, Tang L, Li Y (2014) A mass diffusion-based interpretation of the effect of total solids content on solid-state anaerobic digestion of cellulosic biomass. Bioresour Technol 167: 178-185.

38. Aguilar MAR, Fdez-Güelfo LA, Álvarez-Gallego CJ, García LIR (2013) Effect of HRT on hydrogen production and organic matter solubilization in acidogenic digestion of OFMSW. Chem Eng J 219: 443-449.

39. Hernanández M, Rodríguez M (2013) Hydrogen production by anaerobic digestion of pig manure: Effect of operating conditions. Renewable Energy 53: $187-192$

40. Xiao L, Deng Z, Fung KY, Ng KM (2013) Biohydrogen generation from anaerobic digestion of food waste. Int J Hydrogen Energy 38: 13907-13913.

41. Zhu H, Stadnyk A, Béland M, Seto $P$ (2008) Co-production of hydrogen and methane from potato waste using a two-stage anaerobic digestion process. Bioresour Technol 99: 5078-5084.

42. Wang W, Xie L, Luo G, Zhou Q (2013) Enhanced fermentative hydrogen production from cassava stillage by co-digestion: The effects of different cosubstrates. Int J Hydrogen Energy 38: 6980-6988.

43. Liu H, Fang $\mathrm{HH}(2003)$ Hydrogen production from waste water by acidogenic granular sludge. Water Sci Technol 47: 153-158. 